\title{
Reaching the Roof of the World: Assessing the SRHR Beliefs of Communities Residing in the Highest Mountain Ranges in the World for Integration of Life- skills Based Education in School Curricula
}

\author{
Junaid-Ur-Rehman Siddiqui*, Hira Mustafa Khan, Maha Islam, Sana Tajuddin and Aisha Ijaz \\ Aahung, Sasi Homes, G-18/6, Block 8, Clifton, Karachi, Pakistan \\ ${ }^{*}$ Corresponding author: Junaid-ur-Rehman Siddiqui, Aahung, Sasi Homes, G-18/6, Block 8, Clifton, Karachi, Pakistan
}

Received: March 08, 2021; Accepted: March 15, 2021; Published: March 24, 2021

\begin{abstract}
The Gilgit-Baltistan (GB) region of Pakistan is home to the highest mountains in the world, and the communities residing here are largely disconnected from development efforts dedicated to Sexual and Reproductive Health and Rights (SRHR) in Pakistan. In Gilgit-Baltistan, the unique topography and isolated nature of communities residing at high altitudes makes it challenging for SRHR programmers to firstly access these communities and, secondly, understand their prevalent beliefs and practices. Aahung is a Karachi-based NGO which is planning to pilot a curriculum for Life-Skills Based Education (LSBE) in schools in GB; however, with limited information available, we conducted formative research to inform curriculum design. The aim of this study is to understand the prevalent SRHR beliefs and practices with adolescence and gender as the crosscutting themes. 25 Focus Group Discussions (FGDs) were conducted with 148 total participants in different districts of GB to assess the SRHR-related needs of adolescents in the region. Approximately 34 teachers, 36 parents, and 78 students between grades 6-10 participated in the study. All FGDs were separated by gender and the students were further divided into 2 groups: Grades 6-8 and Grades 9-10. FGD guides and consent forms were developed in English and translated into Urdu. Data were transcribed and thematically analyzed by researchers to identify the SRHR and health-related needs of adolescents in the studied region. Apart from the general prevalence of poor SRHR information among young people, findings showed a significant gender difference in SRHR knowledge and practices. Boys stated several sources of SRHR information, madrasah being the key one, whereas, girls shared that although they could receive some guidance regarding puberty from madrasah, friends and female family members, even their mothers were reluctant in discussing SRHR with them in greater detail. Findings from the study will be used to inform the design of a Life-Skills Based Education (LSBE) curriculum which will be piloted with schools in GB.
\end{abstract}

Keywords: VLSBE, SRHR, Education, Gilgit-Baltistan, Adolescent, Gender

\section{Introduction}

Adolescence is a complex phase for any individual; it is the time for crucial development and change [1]. Perceptions drawn and normative behaviours adopted during this phase need to be more informed than at any other stage of life. As puberty onsets, the beginning of new biological and psychological processes drives many vital changes during this transitional phase [2]. At this stage, occurrences such as menstruation in girls, nocturnal emission in boys, and emotional adjustments in both can create difficulty in their lives, resulting in feelings of confusion and isolation [3]. These changes combined with various other experiences around the time of adolescence can impact an individual's susceptibility to mental health problems [4]. To be able to effectively deal with this transition, adolescents do not only require information and clarity regarding their bodily, emotional, and social changes, but also need to be protected from adverse experiences such as violence, lack of familial support, and enforcement of myths around adolescence [4]. Accurate information and promotion of their psychological well-being at this time can save them from physical discomfort, mental health issues, guilt, confusion, and ambiguity, because any such grief can ultimately affect their social roles [5].

In Pakistan, adolescents are generally poorly informed about their sexual and reproductive health and rights (SRHR) issues including puberty, gender, marriage, family planning, and sexual concerns and sexuality [6]. Especially in the rural areas, owing to the cultural rigidity as well as the sensitive nature of this topic, young people are kept deprived of information around SRHR- related issues from their elders, including their parents and teachers $[7,8]$. A study conducted with school-going children from the ages of 13 to 19 in Gilgit-Baltistan (GB), a largely rural region (rural population in $\mathrm{GB}=83 \%$ ), found that only $62 \%$ of the young respondents had some knowledge of puberty, whereas $91 \%$ were in need of proper guidelines on the topic $[8,9]$. The same study showed that due to lack of education on the subject, almost all respondents (96\%) expressed the desire to learn about reproductive health. The study placed immense blame on low literacy and lack of 
Junaid-Ur-Rehman Siddiqui (2021) Reaching the Roof of the World: Assessing the SRHR Beliefs of Communities Residing in the Highest Mountain Ranges in the World for Integration of Life-skills Based Education in School Curricula

communication between the growing children and elders; it was found that $85 \%$ of adolescence exclusively discussed academics with parents and refrained from engaging in conversations around bodily changes and about other personal matters [8].

This lack of communication is compounded by the poor state of education, which can manifest as negative SRHR behaviours among adolescents $[7,10]$. In GB, only $35 \%$ children of secondary school-going age are attending secondary school [9]. Past researches have also shed light upon the gender-biased education system in GB, wherein, girls suffer more at the hands of illiteracy in comparison to boys $[9,11,12]$. According to the 2017 report of Pakistan Education Statistics, the Gross Enrolment Ratio (GER) in Pre-Primary Education in GB is $42 \%$ and it drops to 38\% for Secondary Education [12]. Another UNICEF survey in 2017 found that the girls-to-boys ratio for Education Gender Parity Index (GPI) across various households, divisions, and districts of GB stands at 0.78 [9]. The out-of-school gender parity in GB speaks volumes about the prevalence of gender discrimination in GB: at primary level, more than half of the out-of-school is that of girls; and in case of secondary level the number rises to a distressing 77\% [9]. The landscape of GB is characterized by harsh physical and mountainous environment where travelling and communication are generally difficult [11]. The situation, therefore, automatically becomes worse for girls, whose parents are less likely to allow them to continue their education in circumstances when security and safety is compromised or where there are transportation problems [13]. Girls' autonomy is further restricted by religious sensitivities and traditions that contribute to their early marriages resulting in discontinuation of education [14]. Low knowledge around SRHR among youth and the obvious gender disparity in the region strongly advocates the need for Comprehensive Sexuality Education (CSE) in schools. Evidence indicates that when provided with CSE, adolescents are better able to tackle SRHR-related challenges in a healthier and more informed way, leading to a positive long-term impact on their lives [15].

This paper illustrates the prevalent perceptions, knowledge, and behaviours around adolescent SRHR in Gilgit-Baltistan along with the needs of young people regarding the same. The findings will be used to design a Life-Skills Based Education [LSBE] programme which will contain CSE modules as well.

\section{Methods}

This study used an exploratory qualitative design and collected data through Focus-Group Discussions (FGDs). Based on saturation of information and minimum representation from all geographical areas, 28 FGDs were conducted with 148 total participants in districts Skardu, Hunza, and Nagar of the Gilgit-Baltistan region. Aahung, a Karachibased NGO, in partnership with a school network in Gilgit-Baltistan, will develop a module for LSBE and will pilot it in selected schools in the study districts. Participants for the FGDs were recruited through the partner school network's management. All key stakeholders for the LSBE pilot, children studying in the schools, parents of the children, and teachers in the partner schools, participated in the study. Data were collected from approximately 34 teachers, 36 parents, and 78 students between Grades 6-10 participated in the study. The distribution of study participants is presented in the table below.
Semi-structured discussion guides were developed for each type of study participant. Besides sociodemographic information from study participants, key thematic areas included perceptions around human rights, gender, health, puberty, substance use, mental health, violence, marriage, familial relationships, and LSBE in general. The discussion guides were developed in English and translated into Urdu. The discussion guides were shared with the school management for review and their feedback was incorporated into the guides. This was done by the researchers to ensure that the tools were culturally appropriate and the language was easily understood by participants. FGDs were conducted in September 2019 by the research team. FGDs were conducted in classrooms in partner schools and each FGD lasted 60-120 minutes.

All of the audio-recorded discussion guides were transcribed verbatim and translated into English. A team of four qualitative researchers conducted the analysis. Data analysis was conducted manually using the framework analysis approach [16,17]. Data analysis was conducted by the research team, based on three types of coding: sub themes, themes, and categories. The identified codes, themes, and patterns were reviewed alternately by each researcher to minimize bias and to ensure reliability. The identified themes and subthemes are organized in the table below.

Informed consent was obtained from all participants. Since data were collected from children, special measures were taken to protect their interests by obtaining parental consent for all participating children beforehand.

\section{Results}

\section{Perceptions around Human Rights}

Participants conceptualized rights to be granted by a higher power; however, they indicated that these rights or the provision of

Table 1: Number of FGDs by district and by type of participant.

\begin{tabular}{|l|c|c|c|c|c|c|c|c|c|}
\hline & Mothers & Fathers & $\begin{array}{c}\text { Male } \\
\text { Teachers }\end{array}$ & $\begin{array}{c}\text { Female } \\
\text { Teachers }\end{array}$ & $\begin{array}{c}\text { Grade } \\
6-8 \\
\text { Boys }\end{array}$ & $\begin{array}{c}\text { Grade } \\
9-10 \\
\text { Boys }\end{array}$ & $\begin{array}{c}\text { Grade } \\
6-8 \\
\text { Girls }\end{array}$ & $\begin{array}{c}\text { Grade } \\
9-10 \\
\text { Girls }\end{array}$ & Total \\
\hline Skardu & 2 & 2 & 2 & 2 & 1 & 1 & 1 & 1 & 12 \\
\hline Hunza & 1 & 1 & 1 & 1 & 1 & 1 & 1 & 1 & 8 \\
\hline Nagar & 1 & 1 & 1 & 1 & 1 & 1 & 1 & 1 & 8 \\
\hline Total & 4 & 4 & 4 & 4 & 3 & 3 & 3 & 3 & 28 \\
\hline
\end{tabular}

Table 2: Identified Themes and Sub-themes.

\begin{tabular}{|l|l|l|}
\hline$\#$ & Themes & Sub-themes \\
\hline 1 & $\begin{array}{l}\text { Perceptions around Human } \\
\text { Rights }\end{array}$ & $\begin{array}{l}\text { Equal treatment } \\
\text { Necessities of life }\end{array}$ \\
\hline 2 & Perceptions around Gender & $\begin{array}{l}\text { Meaning of Gender Perceptions around Boys } \\
\text { Perceptions around Girls }\end{array}$ \\
\hline 3 & Perceptions around Puberty & $\begin{array}{l}\text { Sociocultural Practices and Restrictions } \\
\text { Perceptions around Menstruation and Menstrual } \\
\text { Hygiene }\end{array}$ \\
\hline 4 & Perceptions around Marriage & $\begin{array}{l}\text { Marriage norms } \\
\text { Problems Associated with Early Marriage }\end{array}$ \\
\hline 5 & $\begin{array}{l}\text { Perceptions around Mental } \\
\text { Health }\end{array}$ & $\begin{array}{l}\text { Common Mental Health Issues Sources of Mental } \\
\text { Distress Linkages with Substance Use } \\
\text { Perceptions around Violence }\end{array}$ \\
\hline
\end{tabular}


these rights is muddled through corrupt states. Fulfillment of societal obligations, physiological and safety needs, love and belonging needs, freedom of choice, and equal respect were identified as an individual's rights. Furthermore, participants believed that boys and girls should have equal rights, and should be respected equally.

"There are two types of rights. God's rights and human being's rights. Prayer, fasting, and Zakat ${ }^{1}$ are God's rights. Human being's rights are duties to one other such as neighbour's rights, parents' rights, and teachers' rights."

\section{Young boy, Grade 6-8, Skardu, Gilgit-Baltistan}

Participants shared that their certain fundamental human rights were affected by tourism and locals alike whereby the sensitive biodiversity of the area was being damaged resulting in high water and land pollution as well as hunting of animal species native to the region. Participants specifically mentioned behaviours such as littering in streams of drinking water and valleys and noise pollution from tourist vehicles.

\section{Perceptions around Gender}

Gender was mainly described as the difference between male and female whereas some identified it as the difference in social functioning. Social functions commonly associated with boys were out-of-home chores, bread winning, and physical labour, acting as the first line of defence in war, and supporting parents in old age.

"Boys go to the market. Boys can ride a bike but girls cannot. They don't go to the market.

Boys can go anywhere but girls can't go to most places".

Young boy, Grade 6-8, Hunza, Gilgit-Baltistan

Participants said that girls are not given cell phones and bicycles, neither are they allowed to stay outside the house past sunset, which indicates that the girls' physical as well digital mobility is restricted. Girls are expected only to wear loose-fitting clothes or remain concealed in pardah ${ }^{2}$ and it is considered inappropriate for girls to laugh in front of boys and usually only talk to boys when it is workrelated. Most girls, however, are not given the opportunity to pursue higher studies and those who do pursue higher education are restricted to teaching and medical jobs.

"In our society, girls don't get jobs and stay at home".

Male parent, Nagar, Gilgit-Baltistan

Girls in GB are also not given their due right in inheritance and this contributes to their inability to attain socio-economic independence. Participants also agreed that there are more limitations and accountability in case of girls, whereas, boys are usually absolved of blame.

"Boys are given more information about society and if a boy is guilty of something, the blame is passed on to the girl."

Female teacher, Hunza, Gilgit-Baltistan

Zakat ${ }^{1}$ is an annual alms tax that each Muslim is expected to pay as a religious duty and that is used for charitable purposes [18].
$\operatorname{Pardah}^{2}$ ("veil" or "curtain") is a religious practice that involves the seclusion of women from public observation by means of concealing clothing [19].

\section{Perceptions around Puberty}

Participants associated puberty with becoming an adult, which is signified by the end of years of playfulness and the time to get married. Sharing their views on puberty, some participants said that this is when adolescents become disobedient, emotionally low, and are likely to engage in substance use and other 'sins'.

Girls associated puberty with periods and associated it with sadness. Female participants listed activities exclusive to the days of menstruation: changing of bed sheets/covers, changing the pad/cloth twice to thrice a day, hiding from males, skipping school, washing and ironing the period cloth, and following remedies for period pain. Common remedies included eating boiled eggs with peanuts, drinking milk, remaining seated to limit physical activity, and taking medicine as a last resort. Participants shared that in order to not appear unwell; they had to pretend to work during menstruation.

"We work in the house every day and even if we have painful cramps, we keep working so that the males don't find out."

\section{Young girl, Grade 9-10, Skardu, Gilgit-Baltistan}

Sharing their sources of information on puberty and adolescence, participants listed parents, siblings, cousins, friends, older girls/boys, teachers, school principals, and the internet. A major source cited by both boys and girls, was madrasah where they are given lessons on puberty by the moulvi ${ }^{3}$ using the textbook: "Tauzeeh-ul-Masail ${ }^{4}$.

\section{Perceptions around Marriage}

Participants shared that the normative age for marriage for a girl in GB is 15 to 20 years, or when the girl is in her first or second year of college. Normative age for marriage for boys, in GB, was shared to be within the range of 18 to 25 years. The participants, however, believed the ideal age should range from after puberty to 30 years. Commenting on the problems that stem from early marriages, participants relayed that they can result in early-age pregnancies and large families.

\section{Perceptions around Mental Health}

One participant described mental health as 'feeling fresh' while others automatically assumed a negative line and related it to stress, tension, pressure, frustration, depression, low self-esteem, inferiority complex, psychological problems, obsessions, and not finding peace. Discussing the GB community's perceptions around mental health and mental illness, participants said that "pagal" (crazy) was usually considered synonymous with mentally ill.

"People are generally scared of the "powerful" ones and do not annoy them, where as the "weaker" ones are made fun of and teased. The powerful ones damage people's property and should be locked in a room".

\section{Male parent, Nagar, Gilgit Baltistan}

Moulvi $^{3}$ is a learned teacher or doctor of Islamic law [20]. 
Junaid-Ur-Rehman Siddiqui (2021) Reaching the Roof of the World: Assessing the SRHR Beliefs of Communities Residing in the Highest Mountain Ranges in the World for Integration of Life-skills Based Education in School Curricula

Tauzeeh ul Masail ${ }^{4}$ is a book of Islamic laws compiled by a Shi'a Muslim scholar [21].

On the subject of suicides, participants believed that only boys or men commit suicide, and never women, because men are more distressed. Moreover, on the matter of substance use, participants relayed that people residing outside of their localities, such as in Punjab or Karachi, are associated more with using substances. Substance use was associated with bad upbringing and the most commonly stated reasons for substance abuse were distress/depression, peer pressure, and influence of elders. Some believed that it is a way of celebrating new-found freedom amongst growing boys, and mainly associated it with recreation.

\section{Discussion}

Results of this analysis will be used to modify the LSBE program to be implemented into participating schools in 2020. The revised module will acknowledge the existing knowledge base that the children of GB have, from going through the madrasah system, rather than contradicting it. The programme will be tailored to the community's beliefs and practices, and will integrate the teachings of the madrasah into the curriculum to prevent epistemological and pedagogical conflict. The content of the curriculum will be shared with parents, teachers, and school management before its implementation with children.

During the discussions, participants were reluctant to share information that they believed would reflect negatively on their community. Therefore, a shared form of communal protection was demonstrated with participants explicitly telling each other not attribute "blame" for problems such as substance use to the community itself. This could also be a function of courtesy bias whereby participants provided positively-framed answers to please the interviewers [22]. The study found that all participants had limited pubertal knowledge and shared that SRHR is considered to be a very taboo subject in these communities. Findings showed that parents do not talk to their children about puberty, and mothers specifically do not talk to their daughters about menstruation. These findings contrast starkly from the prevalent beliefs and practices in the rest of the country where mothers serve as the primary source of SRHR knowledge for girls while boys generally gain their knowledge through other sources [23]. All participants cited the madrasah as their source for all pubertal and SRH knowledge. Children, when they "hit puberty", are sent to the madrasah whereby they're provided Islamic religious texts on the subject. Participants had little knowledge on the biological and mental changes caused by puberty, and also conceptualized puberty as a singular point rather than a liminal process. Moreover, despite the community's progressive insistence towards girls' education, patriarchal and heteronormative beliefs prevail which hinders' girls and women from claiming bodily autonomy and rights to inheritance, to work, to choose time of marriage, to choose to divorce, and to choose to procreate [24].

Modules focusing on career and educational choices should be developed as well with a gendered nuance to provide children with knowledge about avenues and resources that exist. Modules should also be developed as well on social responsibility towards the culture and the environment. Moreover, the madrasah system with the textbook appears to be a structural system for disseminating pubertal information among adolescents. The book should be reviewed prior to module development to ensure a "parallel" system is not created which could spark negative reaction from the community.

\section{Conclusion}

This was one of the first studies which specifically explored the SRHR beliefs and perceptions of communities residing in GilgitBaltistan. Apart from prevalence of low knowledge and misconceptions around puberty, marriage, and mental health, gender inequality was discovered as a strong theme lacing most of their SRHR beliefs and social behaviours. Greater emphasis needs to be placed on eliminating and/or transforming beliefs and attitudes that lower women's position within a household and in society. The findings of this study will be used to inform the design of a LSBE module as well as a research trial to test the efficacy of the module. Future studies should also focus on 1) understanding the madrasah system better and the impact it has on shaping the community's SRHR beliefs, and 2) exploring parental and community inclusion in interventional designs for improving adolescents' SRHR.

\section{References}

1. Özdemir A, Utkualp N, Palloş A (2016) Physical and Psychosocial Effects of the Changes in Adolescence Period. Int J Caring Sci 9: 717-723.

2. McNeely C (2011) The teen years explained: a guide to healthy adolescent development. U.S.: Johns Hopkins Bloomberg.

3. Najam N, Hussain S (2015) Gender and mental health in Gilgit-Baltistan, Pakistan J Pioneer Med Sci 5 .

4. World Health Organization. Adolescent mental health [Internet]. www.who.int. 2019

5. Morris JL, Rushwan H (2015) Adolescent Sexual and Reproductive Health: The Global challenges. Int J Gynecol Obstet 131: S40-42. [crossref]

6. Population Council, UKAid, UNFPA (2019) Situation Analysis of Reproductive Health of Adolescents and Youth in Pakistan. Islamabad, Pakistan.

7. Khan A (2003) Adolescent Reproductive Health in Pakistan: Status, Policies, Programs and Issues.

8. Mamdani KF, Hussain A (2015) An evaluation of communication patterns between parents and children regarding puberty: a case study of Skardu, Gilgit-Baltistan. New Horiz 9: 47-65

9. Planning \& Development Department, Government of the Gilgit-Baltistan, UNICEF Pakistan. GB Multiple Indicator Cluster Survey, 2016-17. Gilgit, Pakistan: P\&D Department, Government of the Gilgit-Baltistan and UNICEF Pakistan. 2017.

10. Andalón M, Williams J, Grossman M (2014) Empowering Women: The Effect of Schooling on Young Women's Knowledge and Use of Contraception [Internet]. Cambridge, MA: National Bureau of Economic Research. p. w19961. Report No.: w19961.

11. Murtaza KF (2012) Women Empowerment through Higher Education in GilgitBaltistan. Int J Acad Res Bus Soc Sci 2: 343-367.

12. Shah Dr D, Amin N, Kakli MB, Piracha ZF, Muhammad Adeel Zia (2018) Pakistan Education Statistics 2016-2017. 25th ed. Islamabad: National Education Management Information System (NEMIS), Academy of Educational Planning and Management (AEPAM) with technical and financial support from United Nations Children's Fund (UNICEF), Pakistan.

13. Ali SW, Akhunzada T (2015) Unheard voices: engaging youth of Gilgit-Baltistan. Conciliation Resources, UK and Centre for Peace, Development and Reforms, Pakistan. 
Junaid-Ur-Rehman Siddiqui (2021) Reaching the Roof of the World: Assessing the SRHR Beliefs of Communities Residing in the Highest Mountain Ranges in the World for Integration of Life-skills Based Education in School Curricula

14. Baig S, Ullah A (2017) Outcome and Roots of Early Marriages in Gilgit-Baltistan: A Quantitative Descriptive Study. J Mt Area Res 3: 1-7.

15. Bashir Q, Usman A, Amjad A, Amjad U (2017) 'The Taboo that Silences': Awareness about Sexual and Reproductive Health Issues among Adolescent Females during Pubertal Transition. Isra Med J 9: 381-385.

16. Gale NK, Heath G, Cameron E, Rashid S, Redwood S (2013) Using the framework method for the analysis of qualitative data in multi-disciplinary health research. $B M C$ Med Res Methodol 13: 117. [crossref]

17. Jane R, Liz S. Qualitative Data Analysis for Applied Policy Research. In: The Qualitative Researcher's Companion [Internet]. 2455 Teller Road, Thousand

18. Oaks California 91320 United States of America: SAGE Publications, Inc 305-329.

19. Merriam-Webster. Zakat. In: Merriam-Webster.com [Internet]. 2020 [cited 2020 Apr 23].
20. Pardah. In: Encyclopaedia Britannica [Internet]. Encyclopædia Britannica, inc.; 2008 [cited 2020 Apr 23].

21. Merriam-Webster. maulvi. In: Merriam-Webster.com [Internet]. 2020 [cited 2020 Apr 23].

22. As-Sayyid Ali Al-Husseini As-Seestani. Islamic Laws: English Version of Tawdheehil Masaael [Internet]. Imam Ali Foundation; 2016.

23. Hameed W, Ishaque M, Gul X, Siddiqui J-R, Hussain S, et al. (2018) Does courtesy bias affect how clients report on objective and subjective measures of family planning service quality? A comparison between facility- and home-based interviews. Open Access J Contracept 9: 33-43. [crossref]

24. Ali TS, Rizvi SN (2010) Menstrual knowledge and practices of female adolescents in urban Karachi, Pakistan. J Adolesc 33: 531-541. [crossref] 